\title{
The light fantastic: PHOTON materials for technician education
}

\section{Nicholas Massa, Barbara Washburn, Judith Donnelly, Fenna Hanes}

Nicholas Massa, Barbara Washburn, Judith Donnelly, Fenna Hanes, "The light fantastic: PHOTON materials for technician education," Proc. SPIE 9663, Eighth International Topical Meeting on Education and Training in Optics and Photonics, 96631Y (6 October 2003); doi: 10.1117/12.2207509

SPIE Event: Eighth International Topical Meeting on Education and Training in Optics and Photonics, 2003, Tucson, Arizona, United States 


\title{
The light fantastic: PHOTON materials for technician education
}

\author{
Nicholas Massa and Barbara Washburn \\ Springfield Technical Community College, 1 Armory Square, Springfield, MA \\ massa@stcc.edu; washburn@stcc.edu \\ Judith Donnelly \\ Three Rivers Community College, 7 Mahan Drive, Norwich, CT 06030 \\ jdonnelly@trcc.ccommnet.edu \\ Fenna Hanes \\ New England Board of Higher Education, 45 Temple Place, Boston, MA 02111 \\ fhanes@nebhe.org
}

\begin{abstract}
Project PHOTON has developed a set of instructional materials suitable for a onesemester laboratory based introduction to photonics course. The textbook, laboratory experiment kit and laboratory manual have been thoroughly field tested by participating high schools and two year colleges. All materials have been aligned to national Math, Science, Technology and Language Arts standards.

OCIS codes: (000.0000) General
\end{abstract}

\section{Introduction}

In August 2000, when Project PHOTON received funding from the Advanced Technology Education (ATE) program of the National Science Foundation (NSF), only three community colleges in New England were offering programs in photonics and high school optics labs were a rarity. The goal of the project was to increase the number of middle schools, high schools and colleges in the six New England states teaching units or courses in optics/photonics. Project PHOTON's strategy included

- Providing professional development for teachers to increase the number of instructors qualified to teach optics/photonics

- Providing professional development for career and guidance counselors to enable them to speak knowledgeably about careers in optics/photonics

- Developing alliances among educators at the middle school, high school and college levels to facilitate articulation among levels of instruction

- Developing partnerships between educators and industry to provide school-to-career activities for students and support for classroom learning

- Increasing student interest in optics/photonics by creating hands-on activities to supplement classroom learning

- Improving the lab facilities at participating schools through the development of a laboratory experiment kit.

Recognizing that many science and technology teachers either never studied optics or need an update on modern applications, PHOTON featured a strong teacher professional development component. Career counselors were included in workshops and activities to equip them with outreach information to encourage students interested in careers in science, math, engineering and technology.

Project participants met at initial two-day workshops held in Connecticut and Massachusetts in Fall 2000. The first day of the workshop was held at a corporate location (Zygo Corp, in Middlefield, CT and Lucent, in North Andover, MA). At each workshop, teachers and counselors from 30 schools received an introduction to photonics technology and listened to speakers from industry and academia discussed pathways in photonics education and careers. The second day was for teachers only. Workshops held at college locations (Three Rivers Community College in Connecticut and University of Massachusetts in Lowell, MA) provided teachers with take-home activities for multiple grade levels based on the Optical Society of America (OSA) Optics Discovery Kit. The PHOTON team described the upcoming summer workshop, the equipment kit that each school would receive, and responsibilities of participants continuing in the project.

From the initial group of participants, 40 schools were chosen by competitive application to complete the project. Each school team consisted of a teacher and a career counselor, and schools were required to apply as regional 
alliances ideally including one college and one or more high schools and middle schools. Selected teachers attended a one-week workshop in July of 2001 held at Springfield (MA) Technical Community College. The workshop featured technical lectures and hands-on labs for teachers and a one and a half day program for counselors. Teachers worked with materials developed by the PHOTON team, including a custom designed laboratory kit. Opportunities for networking and a joint activity for teachers and counselors were included in the week's schedule. Several members of the project's industry advisory committee, as well as representatives of OSA and SPIE (the International Society for Optical Engineering) were present for all or part of the week.

During the academic year following the summer workshop, teachers worked at their own institutions to create units, courses and even entire programs in optics/photonics technology. Technical assistance was provided to participants by phone, email and personal visits from the PHOTON team. A listserve was created, allowing participants to have ready access to technical and practical curriculum advice from the project team and from each other. Industry mentors from the OSA New England Chapter volunteered to monitor the listserv and continue to take part in lively discussions of topics ranging from change of phase upon reflection from a metal to the merits and disadvantages of spending the senior year of high school in college.

In May 2002, a showcase workshop was held to allow participants to present their school's implementation of the PHOTON project. Sixteen schools made presentations, including three community colleges, 12 high schools and one middle school. Success stories included new high school labs for optics/photonics built at Tantasqua High School in Sturbridge, MA and in Bangor, ME at the United Technologies Center. Sixth graders at Tolland (CT) Middle School are exploring light and lasers in their technology education class, and new photonics courses have been developed at Central CT State University in the School of Technology.

The final PHOTON workshop was held in November 2002 to satisfy requests from teachers for an additional workshop on more advanced topics. The one-day program featured sessions in holography and optical image processing. Topics covered by demonstration and hands-on activities included creation and viewing of reflection holograms, spatial filtering, optical Fourier transforms, and using a $4 \mathrm{f}$ optical data processor to remove unwanted dots and lines from photographic slides.

Although the initial project plan was to create a set of notes for the teacher workshops which would be distributed to participants and to write detailed instructions for using a PHOTON developed laboratory equipment kit, the development of new materials became an important focus of the project. It was evident that suitable text and laboratory materials for teaching a complete introductory optics course at the high school/two year college level were not commercially available for participants to use in their classroom; thus a PHOTON textbook, laboratory experiment manual and teacher manual were developed. The remainder of this paper focuses on the PHOTON materials and future PHOTON development through project PHOTON2.

\section{PHOTON materials}

\section{1 The PHOTON textbook}

If high school and college students encounter optics at all, it is usually toward the end of a full-year physics course. The PHOTON textbook seeks to remedy the situation by providing an introduction to optical science and technology for students who have only a rudimentary knowledge of physics concepts. The math level is algebra/trigonometry, making the text more accessible to high school and first year college students. Practical and natural applications of optics concepts are emphasized, rather than theory and derivations. Like all the PHOTON materials, the text has been thoroughly tested in high school and community college classrooms both as a stand-alone course for nonmajors and as the first course in a laser electro-optics technology program. The text has also served as the basis for one-semester online courses delivered to traditional college students, and it has been used in a corporate training environment.

As originally developed, the "set of notes" consisted of eight "modules". Using feedback from PHOTON participants and potential publishers, the work was subsequently expanded to ten chapters in a more traditional book format. The first chapter is devoted to laser safety. Although some of the optical concepts used in this chapter may not be thoroughly introduced until later in the text, the authors feel strongly that laser safety must be a first priority, even in classrooms featuring only low power Helium Neon lasers and laser pointers. Since many laboratory experiments and demonstrations in optics involve the use of lasers, it is imperative that students gain an early respect for the hazards associated with their use. It is essential that students treat all lasers with care and respect; inculcating safe behaviors at this level will help avoid accidents when students are exposed to lasers of higher power. 
Subsequent chapters follow a fairly traditional exposition of optical science and technology. After an introduction to the nature of light, including an overview of radiometry and photometry concepts and units, geometric optics and wave optics are presented, followed by a full chapter introduction to optical instruments such as the camera, telescope, microscope, and several types of interferometer. The second half of the textbook includes chapters on laser physics and characteristics, laser material processing applications, and introductions to optical fiber, holography and imaging. Each chapter is richly illustrated with diagrams and photographs, many in color, to aid visual learners in understanding the material. Worked out example calculations are included to assist students in understanding the orders of magnitude relevant to the given problem. Always, practical and natural applications of optics concepts are emphasized.

To maximize usefulness of the textbook as a classroom tool, end-of-chapter conceptual questions and problems, including answers to odd numbered problems, are found in every chapter. Complete worked out solutions to the numerical problems are provided in a separate teacher manual. An appendix to the text includes a review of important concepts from mathematics and physics including scientific notation, Greek letters used in optical science and technology, right angle trigonometry, the concept of energy, and significant digits. Such information is vital when students who have not yet studied physics use the textbook in a physical science classroom.

In addition to the complete solutions to all of the chapter problems, the accompanying teachers manual contains alignment of the text materials to national science, mathematics and language arts standards for grades 9-12. This information is useful for teachers who must show that the course based on the text meets educational standards for instruction. Directions for demonstrations using inexpensive equipment are also included to assist teachers in creating stimulating presentations of optical phenomena.

\subsection{Optics explorations}

PHOTON participants included five middle school teachers, several of whom are now actively incorporating optics/photonics into their science or technology classrooms. In order to have hands-on activities at an appropriate level for grades 5-8, a set of six "Explorations" was created for the original PHOTON workshops. Later, the number of Explorations was increased to nine. The activities use commonly found items and OSA Optics Discovery Kit, and the language and math of the Explorations is at an appropriate level for younger students. The Explorations have been thoroughly tested by the students of PHOTON middle school participants, and include experiments such as Exploring Lasers, Exploring Diffraction and Exploring Scattering.

The Explorations may also be used as classroom demonstrations in a high school or college setting. One of the authors (JD) has created a career exploration workshop based on the PHOTON Explorations, offered each spring during a college career conference for high school students.

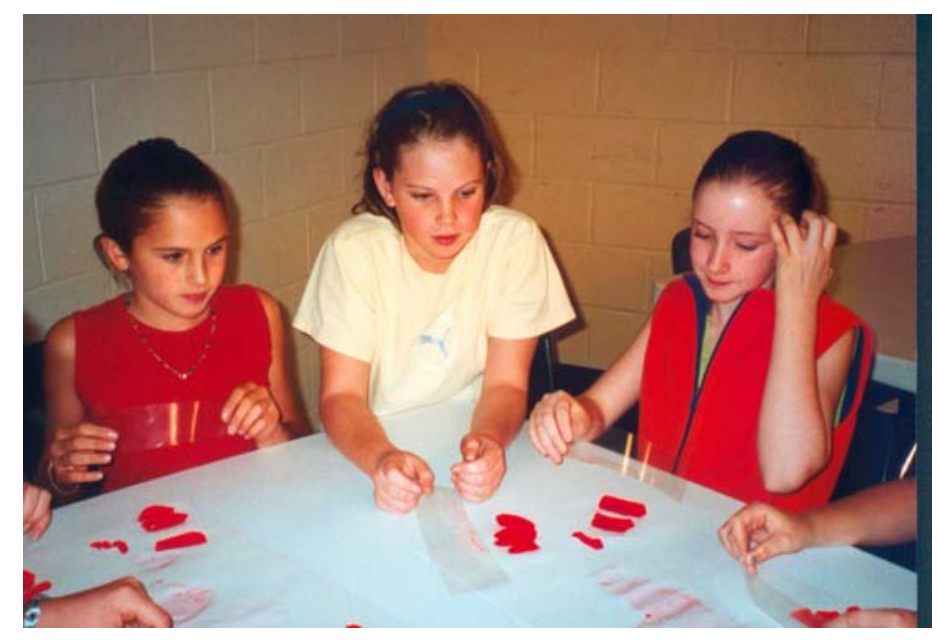

Fig. 1 Tolland Middle School students make lenses out of gelatin in one of the Explorations 


\subsection{PHOTON laboratory kit and experiment manual}

The custom PHOTON laboratory kit was designed to support the experiments in basic and applied optics in the laboratory manual developed by the PHOTON project team. A list of PHOTON lab experiments and explorations is shown in Table 1. Since the summer 2001 workshop, several additional laboratory experiments have been written, and refinement to the lab materials has reclassified some of the labs as "explorations", since they require inexpensive materials and are suitable for students at the middle school level as well as high school and community college.

Table 1. Laboratory experiments and explorations from the PHOTON project

\begin{tabular}{|l|l|}
\hline \multicolumn{1}{|c|}{ EXPERIMENTS } & \multicolumn{1}{c|}{ EXPLORATIONS } \\
\hline Sources of Light & Exploring Light Spectra \\
\hline Plane mirrors & Exploring the Pinhole Camera Viewer \\
\hline Snell's Law & Exploring Reflection \\
\hline Single Lens: The Thin Lens Equation & Exploring Refraction \\
\hline Systems of Two Lenses & Exploring Lasers \\
\hline Laser Beam Collimation & Exploring Scattering \\
\hline Spherical mirrors & Exploring Diffraction \\
\hline Young's Double Slit & Exploring Polarization \\
\hline Michelson Interferometer & Exploring Rayleigh's Criterion and Resolution \\
\hline Interference in an Air Wedge & \\
\hline Diffraction Grating & \\
\hline Malus' Law & \\
\hline Brewster's Angle & \\
\hline Single Slit Diffraction & \\
\hline Laser Range Finder & \\
\hline Laser Bar Code Scanner & \\
\hline Single Beam Reflection Hologram & \\
\hline Two Beam Transmission Hologram & \\
\hline Laser Beam Profile & \\
\hline Numerical aperture of a plastic fiber & \\
\hline
\end{tabular}

An unusual feature of the PHOTON kit is the inclusion of components and component mounts of high quality, the type one might encounter in a research lab or industry, rather than the more commonly encountered aluminum or plastic educational materials from science education supply houses. Not only is the equipment more versatile than the "educational" variety, it is similar to equipment students will see on industry field trips, making the school laboratory experience more relevant to the world of work. Because teachers are largely unfamiliar with this type of equipment, the PHOTON summer workshop devoted each of the five afternoons to learning to assemble and use the equipment.

Half of the approximately $\$ 3000$ cost of each kit was paid for by the PHOTON grant and the remaining $\$ 1500$ was paid by the participating institution. This matching fund requirement was a screening strategy used in the application process to establish which institutions were willing to make a financial commitment to the project. Assistance in locating matching funds was available to schools that showed a strong commitment but were unable to secure funding.

Table 2 lists the equipment and supplies in each of the kits and figure 2 is a photograph of the kit in its bright yellow packing cases. Three light sources were provided: a linearly polarized low power Helium Neon laser, a ray box/multi-feature light source, and a gas tube power supply with Hydrogen and Helium gas tubes. Each kit included a 24 "x36" optical breadboard and a variety of mounting posts, post holders and base plates. The separate lens and mirror kit, plus lens mounts and flat mirrors on kinematic mounts, allowed maximum flexibility for both standard physics labs, such as investigating the thin lens equation, and for more advanced experiments, such as constructing interferometers and laser beam collimators. A small parts box contained the necessary hardware for assembly, plus small items such as a single and double slit slide and a calcite crystal. 
Table 2: PHOTON Laboratory Equipment Kit

\begin{tabular}{|l|l|}
\hline 1 & 24 " x 36" Aluminum optical breadboard tapped 1/4-20 on 1" center \\
\hline 1 & Ray box/Light source \\
\hline 1 & Laser tilt table \\
\hline 1 & HeNe laser, polarized $(0.8$ mWatt) \\
\hline 1 & Spectrum tube power supply with one H spectrum tube and one He spectrum tube \\
\hline 1 & HeNe Optical Power Meter \\
\hline 2 & 1 inch 50/50 Cube beam splitters \\
\hline 2 & Linear polarizers, $42 \mathrm{~mm}$ diameter \\
\hline 2 & Mounted 1" plane front surface mirror \\
\hline 1 & Mounted Objective Lens $\mathrm{f}=8 \mathrm{~mm}$ \\
\hline 1 & Concave spherical mirror front surface $\mathrm{f}=6 \mathrm{~mm}$ \\
\hline 4 & Plane Mirror 50 mm x $50 \mathrm{~mm}$, front surface \\
\hline 2 & Rotary Mount Assembly \\
\hline 2 & Prism Mount Hardware \\
\hline 1 & Single axis translation stage \\
\hline 1 & Plate holder \\
\hline 6 & Lens holders \\
\hline 2 & Small base plate \\
\hline 1 & Large base plate \\
\hline 1 & Microscope Objective Holder \\
\hline 4 each & Plastic Refraction Box \\
\hline 20 & Card mounted diffraction viewers \\
\hline 1 & Flat Glass Plate kit \\
\hline 1 & Quantitative Spectrometer \\
\hline 1 & Iceland Spar Crystal \\
\hline 1 & 1 and 2 slit diffraction slide \\
\hline 1 & Small Parts Kit, including $1 / 4-20$ and $8 / 32$ socket head screws and cap screws; hex keys \\
\hline 1 & Lens and mirror kit (an assortment of 50 mm diameter lenses, flat and spherical mirrors) \\
\hline
\end{tabular}

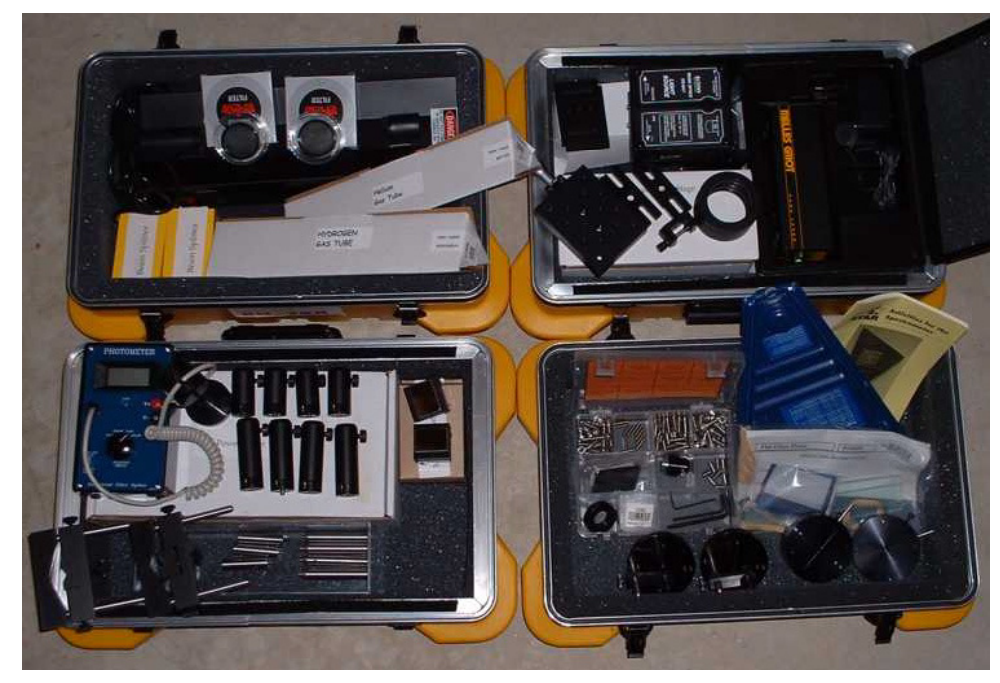

Fig. 2 The PHOTON kit. The lens and mirror kit and breadboard are not shown. 
A unique feature of the PHOTON laboratory kit and experiment manual is that each laboratory procedure was thoroughly tested using the PHOTON kit equipment to ensure that the lab experiments would actually work as intended. The authors have had the frustrating experience of purchasing equipment or lab manuals with poorly designed instructions, or worse, instructions that could not possible work as stated. In order to avoid this situation, each experiment was first tested by the authors and by college student interns before being used by teacher participants in the summer workshop. After the workshop, suggestions for improvements made by participants were incorporated into the next version of the laboratory manual, which was then field-tested by participants' students at their home institutions. Again, feedback from participants was used to produce an edited version of the experiments and new experiments were added on plane and spherical mirrors at participant request.

The final laboratory testing was performed by Sarah Orde, a college student intern who was a graduate of the Greater Hartford Academy of Math and Science in Hartford, CT, one of the PHOTON participant schools. While an instructor might compensate for, or not even notice, small mistakes such as a typographical error or using both upper and lower case letters for the same variable, Ms Orde was an exacting editor. As a result of her input, the lab procedures were further clarified so that, with careful reading by students, an unfavorable laboratory outcome is very unlikely.

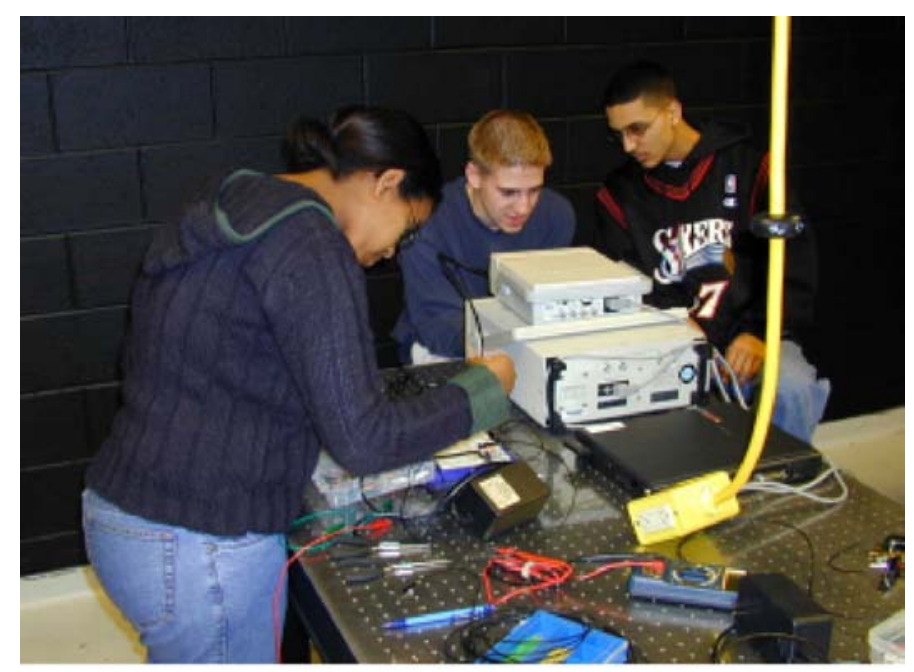

Fig. 3 Students from the Hartford Academy of Math and Science in Connecticut conduct an experiment in photonics. Their instructor is a participant in project PHOTON

\section{PHOTON2}

\subsection{Adapting the PHOTON materials}

The success of PHOTON in achieving its goal of increased courses and programs in optics/photonics in New England schools and colleges has led to NSF funding for PHOTON2, a national dissemination project. The PHOTON materials are now being adapted to distance learning and the resulting course will be taught online to 1012 regional alliances nationwide. Following the PHOTON model, each alliance will include high school teachers, college faculty, career/guidance counselors and local industry.

Additional chapters on optics applications are being added to the textbook and new lab experiments have been created on numerical aperture of a plastic optical fiber and laser beam profile measurements. Additional demonstrations will be added to the teacher manual and a CD-ROM containing videotaped demonstrations of each of the laboratory exercises is being produced.

The components for the initial 40 PHOTON equipment kits were purchased from various vendors and assembled with great effort and enthusiasm by the PHOTON team, student interns and friends. For PHOTON2, LumenFlow, Caledonia, MI, has been contracted to produce the equipment kits and ship them to participants. Minor modifications have been made, for example, a smaller optical breadboard has been found to be more practical and plastic optical fiber will be included. The kit will no longer be packaged in heavy, bright yellow military surplus shipping containers, a change requested by PHOTON participants. 


\subsection{Adapting the Photon Professional Development Model}

Project PHOTON utilized the traditional model of short (two-day and one-week) workshops, within the New England region, to train middle and high school teachers and college faculty in photonics engineering technology. The workshops provided participants with "hands-on" training in photonics curricula, use of laboratory equipment, opportunities for face-to-face interaction with peers and instructors, and exposure to career opportunities. Workshops were supplemented with technical assistance and on-going communication (e.g., phone, email, listserve, and in-person visits) to ensure a high level of support and a continuous learning experience. While the PHOTON project provided an effective model for teacher and faculty professional development on a regional basis, this highly concentrated learning experience had some shortcomings. First, it compressed a great deal of new information into a short timeframe and did not allow the participants sufficient time to reflect and absorb content material. Second, the follow-up to the short-term workshop model required a great deal of technical assistance and on-going communications.

To overcome the limitations of the traditional short-term professional development model and to effectively disseminate the highly successful field-tested PHOTON instructional materials and alliance model nationally, PHOTON2 will employ a web-based distance learning approach supported by the infusion of "adult learning principles" to provide learners with a collaborative, inclusive, and sustained learning environment through the use of modern technology.

\subsection{Utilizing Distance Learning To Disseminate Nationally}

With the advent of the World Wide Web, the use of the Internet for delivery of educational materials, instruction and training has revolutionized higher education. Advantages of web-based courses include the ability for learners to learn at their own pace, access information at a time and place that is convenient to the learner, and communicate easily with instructors and peers (Quintana, 1996). Researchers argue that in contrast to face-to-face instruction, online courses provide learners with extended reflection time through asynchronous dialogue allowing learners to compose thoughtful, probing contributions (Collison, Elbaum, Haavind, \& Tinker, 2000). Web-based instruction allows individuals from around the corner and around the world to come together to form a close-knit community of collaborative learners that capitalizes on professional and common interests.

The format and structure of the PHOTON2 web-course will use collaborative or group learning principles and strategies to facilitate professional development among teachers and faculty. In collaborative learning, instruction is learner-centered rather than teacher-centered and knowledge is viewed as a social construct, facilitated by peer interaction, evaluation, and cooperation (Hiltz, 1998). Fundamentally different from traditional teacher-led instruction, collaborative learning employs instructional methods that encourage learners to work together on academic tasks and construct knowledge and ideas through interactions and responses from others. In collaborative learning, the role of the instructor changes from lecturing to transfer of knowledge to facilitating learner's construction of his or her own knowledge. Research shows that collaborative learning results in more learner involvement with the course, more engagement in the learning process, and is more effective than traditional methods in promoting learning and achievement (Hiltz, 1994; Harasim, 1990; Johnson, 1981). Experts from a number of different fields and from remote geographic locations can "log on" to a threaded discussion on a specific topic and provide insight and fodder for thought that adds richness to the learning experience that would otherwise not be possible. Web-based courses also offer learners instant access to vast amounts of resource material available through the Internet for comparison and research within a dialog. To fully access the benefits available through webbased learning, PHOTON2 will assist teachers and faculty in developing proficiency as web-based learners.

\subsection{Incorporating Adult Learning Principles}

While web-based instruction has many positive aspects, it also has some downsides. These include high dropout rates among learners; a feeling of isolation in the learning process; and a lack of personal connection to instructors and fellow students. Furthermore, instructors who are unfamiliar with the educational framework and support structures necessary for successful self-directed learning may develop web-based versions of traditional curriculum by simply "cutting and pasting" course material into the web-based environment. PHOTON2 will address these issues by designing and developing web-courses from the ground up in collaboration with experts in adult learning to establish a pedagogical foundation of guided inquiry whereby learners construct their own knowledge in the context of a supportive and collaborative learning environment. PHOTON2 Co-PI Dr. Marijke Kehrhahn from the Neag School of Education at the University of Connecticut (UConn), a nationally recognized leader in adult learning methodologies, will oversee the pedagogical aspects of the web-based course development. The project will also 
draw from the expertise of other nationally recognized experts in the field of adult learning and distance education including Dr. Barry Sheckley and Dr. Alexandra Bell from UConn and Dr. Morris Keeton from the University of Maryland University College (UMUC). PHOTON2 will also draw upon the research of the Concord Consortium, an NSF-supported organization involved in the development of effective facilitation of web-based instruction.

The development of the PHOTON2 web-course will be guided by three principles of effective adult learning adapted from Keeton, Sheckley, and Griggs (2002):

Principle 1: Active Learning. Learning that is active results in the development of learner proficiency. Instruction must include hands-on experience, reflection, practice, and feedback to actively engage learners in constructing and organizing a rich knowledge base that they can successfully apply to real problems of practice.

Principle 2: Continuous Learning. Learning that is continuous results in the development of proficiency. Instruction must include sufficient number of contact hours over a span of time to enhance learner processing and problem solving.

Principle 3: Coherent Learning. Learning that is linked to genuine problems of practice results in the development of proficiency. Instruction must be centered around the problems of teaching and program development that faculty face to allow for practice with employing new knowledge in real world contexts.

By integrating strategies that engage learners through active, continuous, and coherent learning within the context of web-based instruction, PHOTON2 will create a collaborative learning environment and experience that will allow learners to: (1) develop the self-directed learning skills necessary to support life-long learning; (2) apply and adapt the content knowledge and learning strategies learned in their own courses and institution; and (3) establish and maintain a collaborative learning community consisting of students, educators, and industry professionals that supports the transfer of learning through synergistic learning activities.

Finally, in addition to providing web-based professional development to teachers and faculty on a national level, PHOTON2 will contribute to the growing body of research on web-based learning. Numerous studies have been conducted to determine the effectiveness of distance education as compared to traditional classroom instruction. (Russell, 1999). While researchers generally report positive results with respect to learning outcomes, they also argue that more research is needed to identify factors related to learning outcomes specifically in the context of webbased instruction (Phipps \& Merisotis, 1999). To address this gap, the PHOTON2 team of researchers will conduct comprehensive quantitative and qualitative analyses throughout the duration of the project to determine the extent to learner characteristics and learning environment, as well as situational and institutional factors relate to learning outcomes and transfer of training. Ongoing formative evaluation and feedback will ensure that teacher and faculty needs are addressed during the course and that the opportunity for learning is maximized. Research results will culminate in peer-reviewed journal publications and a comprehensive guide for effective web-based instructional delivery and facilitation for teacher and faculty professional development.

\section{Conclusion}

Project PHOTON developed curriculum materials for a one semester course in optics/photonics that can be used at the high school or college level, including a draft textbook, laboratory manual, teacher manual and laboratory equipment kit. Using a traditional model of professional development, 40 teachers throughout New England were trained in the use of the materials, and guidance and career counselors were made aware of career opportunities in the field. The materials have been thoroughly tested by PHOTON schools, many of whom now have photonics courses or programs as a result of PHOTON participation.

The PHOTON materials will be further refined and expanded as a result of PHOTON2, a national dissemination project beginning in July 2003. A new model for professional development for teachers and counselors in optics/photonics will also be developed, using distance learning and incorporating adult learning strategies. It is expected that additional courses and programs will be created in schools and colleges nationwide as a result of PHOTON2.

\section{References}

Collision, G., Elbaum, B., Haavind, S., \& Tinker, R. (2000). Facilitating Online Learning: Effective Strategies For Moderators. Madison, WI: Atwood. 
Harasim, L. (1990). Teaching by computer conferencing. In A. Miller (Ed.), Applications of computer conferencing to teacher education and human resource

Hiltz, S.R. (1994). The Virtual Classroom: Learning without Limits via Computer Networks. Norwood, NJ: Ablex Publishing Corporation.

Hiltz, S. R. (1998). Collaborative learning in asynchronous learning networks: Building learning communities. In: WebNet 98 World Conference of the WWW, Internet and Intranet Proceedings, Orlando, FL. ERIC Clearinghouse on Higher Education, 1998. ERIC, ED427705

Johnson, D. W. (1981). Student-student interaction: The neglected variable in education. Educational Research, $10(1), 5-10$.

Keeton, M. T., Sheckley, B. G., \& Griggs, J. (2002). Effectiveness And Efficiency In Higher Education For Adults: A Guide For Fostering Learning. Dubuque, IA: Kendall/Hunt Publishing Company

Phipps, R., \& Merisotis, J. (1999). What's the difference? A review of contemporary research on the effectiveness of distance learning in higher education. The Institute for Higher Education Policy : Washington, DC [Online]. Available: http://www.ihep.com/difference.pdf.

Quintana, Y. (1996). Evaluating the value and effectiveness of Internet-based learning [Online]. Available: http://jargon.itim.mi.cnr.it/inet96/cl/cl_4.htm

Russell, T. L. (1999). The No Significant Difference Phenomenon. Office of Instructional Telecommunications, Chapel Hill, NC: North Carolina State University [Online]. Available: http://cuda.teleeducation.nb.ca/nosignificantdifference/index.cfm

\section{Acknowledgements}

PHOTON: A Curriculum Development, Teacher Enhancement and Laboratory Development Project

Funded in-part by the Advanced Technological Education program of the National Science Foundation.(ATE \#ATE 0053284) Principal Investigator, Judith Donnelly, Three Rivers Community College; Co-Principal Investigators Fenna Hanes (Project Manager), New England Board of Higher Education; John Swienton, Exfo USA, Inc.; Senior Personnel Nicholas Massa and Barbara Washburn, both Springfield Technical Community College

PHOTON2: Web-based Collaborative Learning for Teachers

Funded in-part by the Advanced Technological Education program of the National Science Foundation.(ATE \#ATE 0302528) Principal Investigator, Fenna Hanes (Project Manager), New England Board of Higher Education; CoPrinciple Investigators, Judith Donnelly, Three Rivers Community College; . Marijke Kehrhahn, Neag School of Education (University of Connecticut); Nicholas Massa and Barbara Washburn, both Springfield Technical Community College 